OPEN ACCESS

Edited by: Jan Benes,

Charles University in Prague,

Czech Republic

Reviewed by:

Lars Jakob Bjertnæs,

University of Tromsø, Norway

Andreja Sinkovič,

University Clinical

Centre Maribor, Slovenia

*Correspondence:

Thierry Berghmans

thierry.berghmans@bordet.be

Specialty section:

This article was submitted to

Intensive Care Medicine and

Anesthesiology,

a section of the journal

Frontiers in Medicine

Received: 24 June 2016

Accepted: 25 July 2016

Published: 03 August 2016

Citation:

Fischler R, Meert A-P, Sculier J-P and Berghmans T (2016) Continuous Renal Replacement Therapy

for Acute Renal Failure in

Patients with Cancer: A Well-

Tolerated Adjunct Treatment.

Front. Med. 3:33.

doi: 10.3389/fmed.2016.00033

\section{Continuous Renal Replacement Therapy for Acute Renal Failure in Patients with Cancer: A Well-Tolerated Adjunct Treatment}

\author{
Rebecca Fischler, Anne-Pascale Meert, Jean-Paul Sculier and Thierry Berghmans* \\ Department of Intensive Care and Oncological Emergencies and Thoracic Oncology, Institut Jules Bordet, Université Libre \\ de Bruxelles, Brussels, Belgium
}

Introduction: Acute renal failure (ARF) has a poor prognosis in patients with cancer requiring intensive care unit (ICU) admission. Our aim is finding prognostic factors for hospital mortality in patients with cancer with ARF requiring renal replacement therapy (RRT).

Methods: In this retrospective study, all patients with cancer with ARF treated with continuous venovenous filtration (CVVHDF) in the ICU of the Institut Jules Bordet, between January 1, 2003 and December 31, 2012, were included.

Results: One hundred and three patients are assessed: men/women 69/34, median age 62 years, solid/hematologic tumors 68/35, median SAPS II 56. Mortality rate was $63 \%$. Seven patients required chronic renal dialysis. After multivariate analysis, two variables were statistically associated with hospital mortality: more than one organ failure (including kidney) (OR 5.918; 95\% Cl 2.184-16.038; $p<0.001$ ) and low albumin level (OR 3.341; 95\% Cl 1.229-9.077; $p=0.02$ ). Only minor complications related to CWHDF have been documented.

Conclusion: Despite the poor prognosis associated with ARF, CWHDF is an effective and tolerable renal replacement technique in patients with cancer admitted to the ICU. Multiple organ failure and hypoalbuminemia, two independent prognostic factors for hospital mortality have to be considered when deciding for introducing RRT.

Keywords: intensive care, neoplasms, acute kidney injury, renal dialysis, prognosis

\section{INTRODUCTION}

Acute renal failure $(\mathrm{ARF})$ is a frequent complication in patients with cancer. It may develop due to the cancer itself (multiple myeloma, neoplastic urinary tract obstruction, renal malignant infiltration), its treatment (nephrotoxic chemotherapy, tumor lysis syndrome ...), or secondary complication (sepsis, nephrotoxic antibiotics, iodine contrast administration ...) $(1,2)$. Up to $54 \%$ of patients with cancer admitted to the intensive care unit (ICU) develop ARF and some require renal replacement therapy (RRT) (3-5). Despite improvements in the general management of ICU patients with cancer, $\mathrm{ARF}$ worsens the prognosis. In patient with cancer requiring dialysis, hospital mortality rates are reported between 51 and $90 \%(6-8)$. 
A few published studies are dealing with outcome of patients with cancer with ARF, who required RRT. Results are difficult to compare for several reasons as types and indications of RRT largely varying from one study to another or populations are not comparable. For example, the proportion of solid and hematologic tumors and the number of hematological transplantation were inconstant across the studies while these patients are carrying very distinct prognosis (7-14).

In a first study performed at the Bordet Institute, continuous venovenous hemodiafiltration (CVVHDF) was shown effective for the treatment of ARF in patients with cancer, including solid and hematologic tumors as well as auto- and allograft recipients (15). In the latter small retrospective study, the single independent poor prognostic factor for hospital mortality was the increasing number of organ failures. In another study with a similar case-mix, other authors confirmed the prognostic role of the number of organ failures on hospital mortality (16). As dialysis techniques evolve with time, we aimed at confirming our previously published results on the effectiveness of RRT in a larger cohort of patients with cancer. The primary objective of this retrospective study was the search of prognostic factors for hospital mortality in this group of patients that could eventually help in guiding decision of RRT.

\section{PATIENTS AND METHODS}

All consecutive patients admitted in the medical ICU of the Institut Jules Bordet between January 1, 2003 and December 31, 2012 were recorded. The records of the patients with ARF requiring continuous venovenous RRT at admission or during ICU stay were retrospectively reviewed. Only the first episode of ARF requiring RRT was taken into account. Patients with endstage renal diseases requiring chronic dialysis were excluded. The study was approved by the ethical committee of the Institut Jules Bordet.

Acute renal failure was defined as a creatinine increase $>2 \mathrm{mg} / \mathrm{dl}(176 \mu \mathrm{mol} / \mathrm{l})$ in case of pre-existing normal value, or an increase $>1 \mathrm{mg} / \mathrm{dl}$ from the basic value in case of chronic renal failure. Decision for CVVHDF was based on one (or more) of the following characteristics: bicarbonate level $<10 \mathrm{mg} / \mathrm{dl}$, metabolic acidosis $(\mathrm{pH}<7.30)$, uremia $>33.2 \mathrm{mmol} / \mathrm{l}$, kaliemia $>6 \mathrm{mEq} / \mathrm{dl}$, water overload, pericarditis secondary to ARF, uremic encephalitis, severe ionic abnormalities (hyponatremia, hyperphosphoremia), oligoanuria in presence of evolutive ARF.

The following clinical data were retrieved from the patient's charts: gender, age, type of cancer, cancer phase (17) (diagnostic, curative, controllable but no more curable, pivotal or palliative), cancer status (18) (disease under induction therapy, complete remission without or on active anti-cancer treatment, partial remission, stable disease, progression), reason for ICU admission, anticancer treatments including bone marrow transplantation, potential nephrotoxic agents (iodine contrast agent, antibiotics, chemotherapy ...), co-morbidities, ARF etiology, reason for CVVHDF, variables used for the computation of Simplified Acute Physiology Score II (SAPS II) (19).

The following data were collected at start of RRT: furosemide and vasopressive drugs administration, diuresis, blood pressure, heart and respiratory rates, temperature, biological variables, number of organ failures (including renal failure) at the time of ARF, the immunosuppression status according to the Organ Dysfunction and/or Infection (ODIN) score, the presence of an acute respiratory distress syndrome, and mechanical ventilation support.

We also recorded the main characteristics of RRT: duration, CVVHDF parameters, CVVHDF complications. To determine the final outcome of the patient, we assessed the renal function status (complete, partial or absence of return to initial creatinine values), mortality rates (during hospital and ICU stays), the date and cause of death, or last date known to be alive.

\section{Statistics and Data Analysis}

Results are reported as medians and range. Prognostic factors for hospital mortality were tested in univariate analysis. Binary variables were compared by chi-square test or Fischer's exact test. Non-parametric Mann-Whitney tests were used to compare continuous variables. Variables yielding $p$ value less or equal to 0.2 in univariate analysis were entered into a multiple logistic regression. A Hosmer-Lemeshow test was performed to verify the goodness of fit. A $p$ value $<0.05$ was considered statistically significant.

\section{RESULTS}

One-hundred and twelve patients were treated with RRT during the study period. One patient on chronic dialysis was excluded. Incomplete charts led to exclusion of a further 8 cases leaving 103 patients assessable for the final analysis.

The principal characteristics of the population are reported in Table 1. Renal failure primarily of renal origin, occurred in 83 patients, obstructive renal failure in 1 patient and both types combined in 19 patients. Etiologies of renal failure from renal origin were miscellaneous and detailed in Table 2. A combination of nephrotoxic insults was observed in 43 patients (42\%). A number of potentially nephrotoxic drugs were implicated in the development of renal failure: antibiotics/antifungals/ antivirals $(n=45)$, non-steroidal anti-inflammatory $(n=15)$, iodine contrast product $(n=15)$, chemotherapy agents $(n=12)$, furosemide (dose $\geq 500 \mathrm{mg} / 24 \mathrm{~h})(n=10)$, ciclosporine/sirolimus $(n=9)$, sartan/ACE inhibitor $(n=4)$, zoledronic acid/OKT3 $(n=2)$. A combination of nephrotoxics was found in 31 cases.

Criteria to initiate RRT were as follow: blood $\mathrm{pH}<7.3(n=28)$, (oligo)anuria $(n=17)$, uremia $(n=7)$, severe ionic abnormality $(n=6)$, water overload $(n=3)$, uremic encephalitis $(n=1)$, or a combination of these factors $(n=40)$. In one case, the precise indication for CVVHDF can not be retrospectively determined.

\section{CVVHDF Therapy Outcomes}

Extra-renal replacement therapy was CVVHDF in 100 patients, CVVH (continuous veno-venous hemofiltration) and CVVD (continuous veno-venous dialysis) in 1 and 2 cases, respectively. Pre-dilution technique was applied in 54 cases, post-dilution in 35 cases and alternatively both in 12 cases. Median blood flow rate was $180 \mathrm{ml} / \mathrm{min}$ (range: 60-200). Median reinjection fluid rate was $28.6 \mathrm{ml} / \mathrm{kg} / \mathrm{h}$. The median cumulated overall hemofiltration 
TABLE 1 | Characteristics at ICU admission of 103 patients with cancer with acute renal failure requiring renal replacement therapy.

\begin{tabular}{|c|c|}
\hline Sex (male/female) & $69 / 34(67 \% / 33 \%)$ \\
\hline Age (median/range) & 62 years $(19-87)$ \\
\hline Solid malignancies (locoregional/metastatic) & $68(66 \%)(28 / 40)$ \\
\hline Breast & $7(7 \%)$ \\
\hline Lung & $6(6 \%)$ \\
\hline Digestive tract & $15(15 \%)$ \\
\hline Prostate/bladder/kidney & $23(22 \%)$ \\
\hline Other & $17(17 \%)$ \\
\hline Hematological malignancies & $35(34 \%)$ \\
\hline Leukemia & $10(10 \%)$ \\
\hline Lymphoma & $14(14 \%)$ \\
\hline Multiple myeloma & $9(9 \%)$ \\
\hline Myelodysplastic syndrome & $2(2 \%)$ \\
\hline Stem cell transplantation before ICU admission (allo/auto) & $18(14 / 4)(17 \%)$ \\
\hline \multicolumn{2}{|l|}{ Cancer phase } \\
\hline Diagnostic & $9(9 \%)$ \\
\hline Curative & $41(40 \%)$ \\
\hline Controllable & $53(51 \%)$ \\
\hline \multicolumn{2}{|l|}{ Cancer status } \\
\hline Induction & $25(24 \%)$ \\
\hline Diagnostic & $9(9 \%)$ \\
\hline Remission (partial or complete) & 35 (34\%) \\
\hline Stabilization & $1(1 \%)$ \\
\hline Progression & $33(32 \%)$ \\
\hline \multicolumn{2}{|l|}{ Causes of ICU admission } \\
\hline Renal disease & $58(56 \%)$ \\
\hline Shock/sepsis & $20(19 \%)$ \\
\hline Metabolic disorder & $9(9 \%)$ \\
\hline Respiratory failure & $8(8 \%)$ \\
\hline Other & $8(8 \%)$ \\
\hline \multicolumn{2}{|l|}{ Chemotherapy given before ICU admission } \\
\hline Less than 15 days & $35(34 \%)$ \\
\hline More than 15 days & $27(26 \%)$ \\
\hline No & $41(40 \%)$ \\
\hline Immunodepression & $50(49 \%)$ \\
\hline Urinary tract infection & $14(14 \%)$ \\
\hline Diabetes & $14(14 \%)$ \\
\hline \multicolumn{2}{|l|}{ Baseline characteristics at the time of initiation of CWHDF } \\
\hline ARDS & $25(24 \%)$ \\
\hline Mechanical ventilation & $53(51 \%)$ \\
\hline Vasopressors & $43(42 \%)$ \\
\hline Hematological failure & $28(27 \%)$ \\
\hline$>1$ organ failure & $65(63 \%)$ \\
\hline $\mathrm{pH}$ (median/range) & $7.3(7.02-7.52)$ \\
\hline Natremia (mEq/l) (median/range) & $138(122-150)$ \\
\hline Kaliemia (mEq/l) (median/range) & $4.7(2.9-8)$ \\
\hline Creatininemia (mg/dl) (median/range) & $3.76(1.28-20.1)$ \\
\hline Uremia (mg/dl) (median/range) & $151(49-492)$ \\
\hline SAPS II (median/range) & $56(28-99)$ \\
\hline
\end{tabular}

ICU, intensive care unit; SAPS, simplified acute physiology score; allo, allogenic; auto, autologous; ARDS, acute respiratory distress syndrome.

duration was $34.5 \mathrm{~h}$ (range: 2-354 h). Complications of RRT were filter coagulation at least once $(n=32)$, hypotension $(n=3)$ and uncomplicated hemorrhage at the catheter insertion's site $(n=3)$.

Complete or partial (persistent abnormal creatinine value not requiring further RRT) ARF resolution was observed in 27 and 18 patients, respectively. No resolution, defined as required RRT at the time of death $(n=49)$, transfer in another hospital without ARF resolution $(n=2)$, or need for chronic dialysis $(n=7)$, was found in 58 patients.
TABLE 2 | Principal etiologies of acute renal failure in patients admitted in the ICU.

\begin{tabular}{lrc}
\hline & $\boldsymbol{n}$ & $\boldsymbol{\%}^{\mathbf{a}}$ \\
\hline Nephrotoxic drugs & 48 & 47 \\
Shock/sepsis & 41 & 40 \\
Acute tubular necrosis $^{\mathrm{b}}$ & 19 & 18 \\
Cancer & 10 & 10 \\
Tumor lysis syndrome & 8 & 8 \\
MOF & 4 & 4 \\
Hepato-renal syndrome & 4 & 4 \\
Other & 12 & 12 \\
Unknown $^{c}$ & 6 & 6
\end{tabular}

${ }^{a}$ One patient could have had more than one etiological factor: a combination of at least two factors has been seen in 43 patients ( $42 \%$ of the cases).

${ }^{\circ}$ Acute tubular necrosis except nephrotoxic drugs and shock/sepsis.

"No aetiology has been formally identified.

MOF, multiple organ failure.

\section{Patient Survival Outcomes}

Among patients alive at hospital discharge, complete, partial, or absence of ARF resolution was observed in 20, 9, and 9 patients, respectively. Seven patients ( $18 \%$ of the patients alive at the hospital discharge) needed chronic dialysis. Of them, 2 had a multiple myeloma and 5 patients presented with a loco-regional $(n=3)$ or metastatic $(n=2)$ solid tumor. Five of them had prior renal disease: polycystic kidney $(n=2)$, myelomatous kidney $(n=1)$, or a chronic renal failure not requiring dialysis $(n=2)$.

The median duration of ICU and hospital stays were 9 days (range: 1-124 days) and 22 days (range: 1-155 days). Fifty patients died in the ICU and a further 15 in the general ward after ICU discharge. Thirty-eight patients were discharged alive from the hospital. The ICU mortality rate was $49 \%$ and the hospital mortality rate was $63 \%$. The main causes of hospital death were multiple organ failure $(n=21)$, septic shock $(n=16)$, shock from another origin $(n=7)$, cancer $(n=6), \operatorname{ARF}(n=2)$.

Univariate analysis of prognostic factors for hospital mortality is reported in Table 3. All significant variables and those with a $p$-value $<0.2$ in univariate analysis were included in a multivariate analysis. Two variables were statistically independent pejorative prognostic factors for hospital mortality in multivariate analysis: the number of organ failure [Odds ratio $=5.918 ; 95 \%$ confidence interval (CI) 2.184-16.038; $p<0.001]$ and hypoalbuminemia (Odds ratio $=3.341 ; 95 \%$ CI 1.229-9.077; $p=0.02$ ).

At the time of analysis, 90 patients died, and 3 patients were lost to follow up. Median survival of patients discharged alive from hospital was 413 days; it was 157 days for patients on chronic dialysis but 441 days for those independent from dialysis $(p=0.34)$.

\section{DISCUSSION}

In this retrospective study including patients with cancer with ARF requiring RRT, two statistically significant independent prognostic factors for hospital mortality were identified. A higher risk of death was associated with increasing number of organ failures and with low albumin levels. Cancer characteristics and SAPS II score were not associated with outcome. 
TABLE 3 | Prognostic factors for hospital mortality - univariate analysis.

\begin{tabular}{|c|c|c|c|c|}
\hline & & Non-survivors & Survivors & $p$-value \\
\hline \multicolumn{2}{|l|}{ Hematological tumor } & 27 (77\%) & $8(23 \%)$ & \\
\hline \multicolumn{2}{|l|}{ Solid tumor } & 38 (55\%) & $30(45 \%)$ & 0.034 \\
\hline \multicolumn{2}{|l|}{ Age (median) } & 61 years & 64 years & 0.06 \\
\hline \multicolumn{5}{|c|}{ Number of organ failure } \\
\hline \multicolumn{2}{|l|}{1} & $10(29 \%)$ & $24(71 \%)$ & $<0.00001$ \\
\hline \multicolumn{2}{|l|}{$>1$} & 55 (80\%) & $14(20 \%)$ & \\
\hline \multicolumn{5}{|l|}{ Cancer status } \\
\hline \multicolumn{2}{|l|}{ Progression } & 22 (67\%) & $11(33 \%)$ & 0.60 \\
\hline \multicolumn{2}{|c|}{ Other than progression } & $43(61 \%)$ & 27 (39\%) & \\
\hline \multicolumn{5}{|c|}{ Cancer phase } \\
\hline \multicolumn{2}{|l|}{ Diagnostic } & $6(67 \%)$ & 3 (33\%) & 0.23 \\
\hline \multicolumn{2}{|l|}{ Curative } & $21(51 \%)$ & $20(49 \%)$ & \\
\hline \multicolumn{2}{|l|}{ Controllable } & 38 (72\%) & $15(28 \%)$ & \\
\hline \multirow[t]{2}{*}{ Immunodepression } & No & 29 (55\%) & $24(45 \%)$ & 0.07 \\
\hline & Yes & $36(72 \%)$ & $14(28 \%)$ & \\
\hline \multirow[t]{2}{*}{ ARF origin } & Renal & $51(61 \%)$ & 32 (39\%) & 0.43 \\
\hline & Mixed & $13(68 \%)$ & $6(32 \%)$ & \\
\hline \multirow[t]{2}{*}{ Allo/auto graft } & No & 49 (58\%) & $36(42 \%)$ & 0.01 \\
\hline & Yes & $16(89 \%)$ & $2(11 \%)$ & \\
\hline \multirow[t]{2}{*}{ ARDS } & No & 47 (56\%) & 37 (44\%) & 0.001 \\
\hline & Yes & 18 (95\%) & $1(5 \%)$ & \\
\hline \multirow{5}{*}{$\begin{array}{l}\text { Mechanical } \\
\text { ventilation } \\
\text { Vasopressor }\end{array}$} & No & 22 (44\%) & 28 (56\%) & 0.0001 \\
\hline & Yes & 43 (81\%) & $10(19 \%)$ & \\
\hline & No & $30(50 \%)$ & $30(50 \%)$ & 0.002 \\
\hline & Yes & $35(81 \%)$ & $8(19 \%)$ & \\
\hline & & Median (range) & Median (range) & \\
\hline \multicolumn{2}{|l|}{ SAPS ॥ } & 57 (28-99) & $50(26-88)$ & 0.022 \\
\hline \multicolumn{2}{|l|}{ Bilirubinemia (mg/dl) } & $1.4(0.2-19)$ & $0.5(0.1-5.7)$ & 0.0002 \\
\hline \multicolumn{2}{|l|}{ Creatininemia (mg/dl) } & $3.6(1.3-18)$ & $4.8(1.3-20)$ & 0.02 \\
\hline \multicolumn{2}{|l|}{ Uremia (mg/dl) } & $147(55-492)$ & $154(49-485)$ & 0.78 \\
\hline \multicolumn{2}{|l|}{ Natremia (mEq/l) } & $139(122-150)$ & 135 (128-148) & 0.01 \\
\hline \multicolumn{2}{|l|}{ Kaliemia (mEq/l) } & $4.7(3.2-8)$ & $4.5(2.9-7.8)$ & 0.33 \\
\hline \multicolumn{2}{|c|}{ Phosphatemia (mEq/l) } & $6.2(2.9-11.3)$ & $6.1(2.6-14.6)$ & 0.80 \\
\hline \multicolumn{2}{|l|}{ Bicarbonate (mEq/l) } & $19(6-32)$ & $19(3-27)$ & 0.64 \\
\hline \multicolumn{2}{|l|}{ INR } & $1.45(0.97-3.9)$ & $1.33(0.8-2.9)$ & 0.15 \\
\hline \multicolumn{2}{|l|}{ Albuminemia (g/dl) } & $2.5(0.7-4)$ & $3.05(1.7-5.1)$ & 0.0001 \\
\hline Leukocytes $\left(10^{3} / \mathrm{mm}\right.$ & & $7.8(0.02-39)$ & $13(0.05-50)$ & 0.07 \\
\hline
\end{tabular}

SAPS, Simplified acute physiology score; INR, international normalized ratio; ARF, acute kidney injury; ARDS, acute respiratory distress syndrome.

Bold font highlight the significant variables in univariate analysis.

This study confirms that CVVHDF is a feasible and welltolerated RRT in patients with cancer with ARF admitted to the ICU. Prognosis was comparable to previously published studies (Table 4). Detailed comparisons between studies are difficult due to different case-mix, indications and methods of RRT.

As expected, higher mortality was observed when hematological malignancies are considered (9). Two prognostic factors for hospital mortality were highlighted that could be helpful in selecting patients for CVVHDF with better chance to be hospital discharged. The increased number of organ failures has yet been found associated with a pejorative prognosis as well in cancer and general populations $(7,13,15,16,20,21)$. On the opposite, the role of hypoalbuminemia was more controversial in general ICU (22-25) but was not extensively assessed in patients with cancer. A negative effect on mortality of hypoalbuminemia was shown in one study and only in univariate analysis (16). It must be emphasized that the cancer characteristics (status, phase or treatment) were not predictors of hospital mortality.
As previously reported, hospital mortality was linked to acute physiological changes induced by the complications leading to ICU admission while cancer variables influenced significantly survival after hospital discharge $(18,26,27)$.

In addition to the effectiveness of CVVHDF in patients with cancer, this RRT showed also adequate tolerance in this frail population, often immunocompromised due to cancer or its treatment. This observation was rarely reported in the literature. Other authors assessing C-SLED (sustained low efficiency dialysis in the continuous mode) for RRT, reported complication due to hypocalcemia induced by citrate administration for anticoagulation (16). In another publication concerning hematological malignancies, no bleeding was observed despite severe thrombopenia and a catheter infection was documented in $5 \%$ of the patients (11). Patients and physicians need to know that a substantial number of RRT will lead to permanent chronic replacement therapy, despite the documented effectiveness and tolerability of CVVHDF. In our study, $18 \%$ of the patients discharged alive from the hospital required a chronic dialysis. This was in the range between 14 and $24 \%$, which is not different from rates observed in cancer patients $(7,13,14)$ and in general ICU populations (28). It must be emphasized that in our study, five out of these seven patients presented with underlying renal diseases that could have contributed to the final renal status.

In the present study, we observed that half of the patients were exposed to a nephrotoxic drug that could have played a role in ARF development. Among them, anticancer drugs or immunosuppressive agents, the latter in case of bone marrow grafting, have been documented in $18 \%$ of the cases. A number of anticancer treatments are known for their nephrotoxicity with different pathophysiological mechanisms as cisplatin, nitrosourea derivatives, mitomycin, ifosfamide, or methotrexate without being exhaustive. Different preventive methods as adequate hydration (cisplatin) or urine alkalinization (high dose methotrexate) are recommended. Clinicians have to be aware of the poor prognosis of ARF when prescribing potentially nephrotoxic chemotherapy in patient with disturbed renal function and/or at risk for ARF. They also have to consider the risk of ARF when administering nephrotoxic agents after a nephrotoxic chemotherapy as iodine contrast product and/or aminoglycoside after cisplatin administration.

\section{Potential Bias and Limitations}

Some bias related to retrospective studies must be discussed. As all the patients admitted to the ICU were prospectively recorded, a selection bias was unlikely. However, due to limited available data, some files have not been studied. The retrospective nature of our analysis could lead to missing data, which were minimal in our case. The number of patients in our study was limited but was in the same range as for the other publications. As for other unicentric studies, generalization of the results is limited. Nevertheless, our results and conclusion are comparable to previous series suggesting adequate robustness of the data $(13,29)$. Multiple definitions for ARF have been proposed. In this retrospective study, we decided, based on available data, to apply a simple definition of ARF (an increase 
TABLE 4 | Summary of publications assessing renal replacement therapy in patients with cancer admitted into ICU.

\begin{tabular}{|c|c|c|c|c|c|}
\hline Reference & Population & $N$ & RRT & Mortality & Prognostic factors for hospital mortality \\
\hline \multicolumn{6}{|c|}{ Mixed population (solid and hematological tumors, including bone marrow transplantation) } \\
\hline Berghmans et al. (15) & $\begin{array}{l}\text { Solid: } 50 \% \\
\text { Hemato: } 50 \% \\
\text { BMT: } 28 \%\end{array}$ & 32 & CWHDF & $\begin{array}{l}\text { ICU: } 50 \% \\
\text { Hospital: 53\% }\end{array}$ & Number of organ failure \\
\hline Salahudeen et al. (5) & $\begin{array}{l}\text { Solid: } 38 \% \\
\text { Hemato: } 62 \% \\
\text { BMT: } 18 \%\end{array}$ & 199 & C-SLED & Day 30: 65\% & SOFA score, $\mathrm{pH}$, mean blood pressure \\
\hline \multicolumn{6}{|c|}{ Mixed population (solid and hematological tumors, excluding bone marrow transplantation) } \\
\hline Maccariello et al. (13) & $\begin{array}{l}\text { Solid: } 73 \% \\
\text { Hemato: } 27 \%\end{array}$ & 118 & $\begin{array}{l}\text { IRRT daily conventional } \\
\text { IRRT daily extended } \\
\text { CRRT }\end{array}$ & $\begin{array}{l}\text { ICU: } 70 \% \\
\text { Hospital: } 78 \%\end{array}$ & Number of organ failure \\
\hline Darmon et al. (7) & $\begin{array}{l}\text { Solid: } 7 \% \\
\text { Hemato: } 78 \% \\
\text { Other: } 15 \%\end{array}$ & 94 & $\begin{array}{l}\text { CRRT } \\
\text { IRRT }\end{array}$ & $\begin{array}{l}\text { ICU: } 43.6 \% \\
\text { Hospital: } 51.1 \% \\
6 \text { months: } 65.4 \%\end{array}$ & $\begin{array}{l}\text { LOD score, late RRT (>24 h after ICU } \\
\text { admission) }\end{array}$ \\
\hline Soares et al. (14) & $\begin{array}{l}\text { Solid: } 75 \% \\
\text { Hemato: } 25 \%\end{array}$ & 98 & $\begin{array}{l}\text { IRRT conventional } \\
\text { IRRT extended } \\
\text { CRRT }\end{array}$ & Hospital: $64-86 \%$ & - \\
\hline \multicolumn{6}{|c|}{ Hematological tumors } \\
\hline Letourneau et al. (12) & BMT: $100 \%$ & 14 & $\begin{array}{l}\text { CWHDF } \\
\text { IRRT }\end{array}$ & - & - \\
\hline Lanore et al. (11) & BMT: 11\% & 43 & & ICU: $72 \%$ & $\begin{array}{l}\text { ARF secondary to sepsis, SAPS score, } \\
\text { mechanical ventilation support }\end{array}$ \\
\hline Benoit et al. (9) & BMT: $22.4 \%$ & 50 & $\begin{array}{l}\text { IRRT } \\
\text { CRRT }\end{array}$ & $\begin{array}{l}\text { ICU: } 79.6 \% \\
\text { Hospital: } 83.7 \% \\
6 \text { months: } 86 \%\end{array}$ & - \\
\hline
\end{tabular}

Cancer series found by PubMed search using the MESH terms "Acute kidney injury" and "Intensive care."

RRT, renal replacement therapy; CWVHDF, continuous venovenous hemodiafiltration; ICU, intensive care unit; C-SLED, sustained low efficiency dialysis in the continuous mode;

CRRT, continuous renal replacement therapy; IRRT, intermittent renal replacement therapy; BMT, bone marrow transplantation; ARF, acute renal failure.

of creatinine above $2 \mathrm{mg} / \mathrm{dl})$. We did not use creatinine clearance or glomerular filtration rate because we were focusing on clinical settings where the clinicians decided performing RRT, most of the patients having high creatinine values and/or clinical signs of intolerance to ARF (acidosis, water overload ...). Our data could deserve further prospective study in which a more precise definition of ARF should be used as RIFLE criteria or other clearance determination.

In conclusion, although ARF requiring RRT in patients with cancer admitted in ICU still has a poor prognosis, the use of CVVHDF is effective and tolerable in this immunocompromised population. Multiple organ failure and hypoalbuminemia have to

\section{REFERENCES}

1. Benoit DD, Hoste EA. Acute kidney injury in critically ill patients with cancer. Crit Care Clin (2010) 26:151-79. doi:10.1016/j.ccc.2009.09.002

2. Lameire NH, Flombaum CD, Moreau D, Ronco C. Acute renal failure in cancer patients. Ann Med (2005) 37:13-25. doi:10.1080/07853890510007205

3. Bagshaw SM, Laupland KB, Doig CJ, Mortis G, Fick GH, Mucenski M, et al. Prognosis for long-term survival and renal recovery in critically ill patients with severe acute renal failure: a population-based study. Crit Care (2005) 9:R700-9. doi:10.1186/cc3879

4. Libório AB, Abreu KL, Silva GB Jr, Lima RS, Barreto AG, Barbosa OA, et al. Predicting hospital mortality in critically ill cancer patients according to acute kidney injury severity. Oncology (2011) 80:160-6. doi:10.1159/000329042 be considered when deciding to introduce RRT in the treatment of this group of patients.

\section{AUTHOR CONTRIBUTIONS}

All the authors gave substantial contributions to the conception and design of the work, the acquisition, analysis, and interpretation of data for the work. They all revised the manuscript and approved the final version. They agree to be accountable for all aspects of the work in ensuring that questions related to the accuracy or integrity of any part of the work are appropriately investigated and resolved.

5. Salahudeen AK, Doshi SM, Pawar T, Nowshad G, Lahoti A, Shah P. Incidence rate, clinical correlates, and outcomes of AKI in patients admitted to a comprehensive cancer center. Clin J Am Soc Nephrol (2013) 8:347-54. doi:10.2215/ CJN.03530412

6. Azoulay E, Soares M, Darmon M, Benoit D, Pastores S, Afessa B. Intensive care of the cancer patient: recent achievements and remaining challenges. Ann Intensive Care (2011) 1:5. doi:10.1186/2110-5820-1-5

7. Darmon M, Thiery G, Ciroldi M, Porcher R, Schlemmer B, Azoulay E. Should dialysis be offered to cancer patients with acute kidney injury? Intensive Care Med (2007) 33:765-72. doi:10.1007/s00134-007-0579-1

8. Lane PH, Mauer SM, Blazar BR, Ramsay NK, Kashtan CE. Outcome of dialysis for acute renal failure in pediatric bone marrow transplant patients. Bone Marrow Transplant (1994) 13:613-7. 
9. Benoit DD, Hoste EA, Depuydt PO, Offner FC, Lameire NH, Vandewoude KH, et al. Outcome in critically ill medical patients treated with renal replacement therapy for acute renal failure: comparison between patients with and those without haematological malignancies. Nephrol Dial Transplant (2005) 20:552-8. doi:10.1093/ndt/gfh637

10. Hahn T, Rondeau C, Shaukat A, Jupudy V, Miller A, Alam AR, et al. Acute renal failure requiring dialysis after allogeneic blood and marrow transplantation identifies very poor prognosis patients. Bone Marrow Transplant (2003) 32:405-10. doi:10.1038/sj.bmt.1704144

11. Lanore JJ, Brunet F, Pochard F, Bellivier F, Dhainaut JF, Vaxelaire JF, et al. Hemodialysis for acute renal failure in patients with hematologic malignancies. Crit Care Med (1991) 19:346-51. doi:10.1097/00003246-199103000-00011

12. Letourneau I, Dorval M, Bélanger R, Légaré M, Fortier L, Leblanc M. Acute renal failure in bone marrow transplant patients admitted to the intensive care unit. Nephron (2002) 90:408-12. doi:10.1159/000054728

13. Maccariello E, Valente C, Nogueira L, Bonomo H Jr, Ismael M, Machado $\mathrm{JE}$, et al. Outcomes of cancer and non-cancer patients with acute kidney injury and need of renal replacement therapy admitted to general intensive care units. Nephrol Dial Transplant (2011) 26:537-43. doi:10.1093/ndt/ gfq441

14. Soares M, Salluh JI, Carvalho MS, Darmon M, Rocco JR, Spector N. Prognosis of critically ill patients with cancer and acute renal dysfunction. J Clin Oncol (2006) 24:4003-10. doi:10.1200/JCO.2006.05.7869

15. Berghmans T, Meert AP, Markiewicz E, Sculier JP. Continuous venovenous haemofiltration in cancer patients with renal failure: a single-centre experience. Support Care Cancer (2004) 12:306-11. doi:10.1007/s00520-003-0588-8

16. Salahudeen AK, Kumar V, Madan N, Xiao L, Lahoti A, Samuels J, et al. Sustained low efficiency dialysis in the continuous mode (C-SLED): dialysis efficacy, clinical outcomes, and survival predictors in critically ill cancer patients. Clin J Am Soc Nephrol (2009) 4:1338-46. doi:10.2215/CJN. 02130309

17. Haines IE, Zalcberg J, Buchanan JD. Not-for-resuscitation orders in cancer patients - principles of decision-making. Med J Aust (1990) 153:225-9.

18. Sculier JP, Paesmans M, Markiewicz E, Berghmans T. Scoring systems in cancer patients admitted for an acute complication in a medical intensive care unit. Crit Care Med (2000) 28:2786-92. doi:10.1097/00003246-200008000-00018

19. Le Gall JR, Lemeshow S, Saulnier F. A new Simplified Acute Physiology Score (SAPS II) based on a European/North American multicenter study. JAMA (1993) 270:2957-63. doi:10.1001/jama.1993.03510240069035

20. Schwilk B, Wiedeck H, Stein B, Reinelt H, Treiber H, Bothner U. Epidemiology of acute renal failure and outcome of haemodiafiltration in intensive care. Intensive Care Med (1997) 23:1204-11. doi:10.1007/s001340050487
21. Wang IK, Wang ST, Chang HY, Lin CL, Kuo HL, Chen TC, et al. Prognostic value of acute physiology and chronic health evaluation II and organ system failure in patients with acute renal failure requiring dialysis. Ren Fail (2005) 27:663-9. doi:10.1080/08860220500234881

22. Freire AX, Bridges L, Umpierrez GE, Kuhl D, Kitabchi AE. Admission hyperglycemia and other risk factors as predictors of hospital mortality in a medical ICU population. Chest (2005) 128:3109-16. doi:10.1378/chest.128.5.3109

23. Kung SP, Tang GJ, Wu CW, Lui WY. Serum albumin concentration as a prognostic indicator for acute surgical patients. Zhonghua Yi Xue Za Zhi (Taipei) (1999) 62:61-7.

24. McCluskey A, Thomas AN, Bowles BJ, Kishen R. The prognostic value of serial measurements of serum albumin concentration in patients admitted to an intensive care unit. Anaesthesia (1996) 51:724-7. doi:10.1111/j.13652044.1996.tb06194.x

25. Yap FH, Joynt GM, Buckley TA, Wong EL. Association of serum albumin concentration and mortality risk in critically ill patients. Anaesth Intensive Care (2002) 30:202-7.

26. Lecuyer L, Chevret S, Thiery G, Darmon M, Schlemmer B, Azoulay E. The ICU trial: a new admission policy for cancer patients requiring mechanical ventilation. Crit Care Med (2007) 35:808-14. doi:10.1097/01. CCM.0000256846.27192.7A

27. Soares M, Caruso P, Silva E, Teles JM, Lobo SM, Friedman G, et al. Characteristics and outcomes of patients with cancer requiring admission to intensive care units: a prospective multicenter study. Crit Care Med (2010) 38:9-15. doi:10.1097/CCM.0b013e3181c0349e

28. Uchino S, Kellum JA, Bellomo R, Doig GS, Morimatsu H, Morgera S, et al. Acute renal failure in critically ill patients: a multinational, multicenter study. JAMA (2005) 294:813-8. doi:10.1001/jama.294.7.813

29. Taccone FS, Artigas AA, Sprung CL, Moreno R, Sakr Y, Vincent JL. Characteristics and outcomes of cancer patients in European ICUs. Crit Care (2009) 13:R15. doi:10.1186/cc7713

Conflict of Interest Statement: The authors declare that the research was conducted in the absence of any commercial or financial relationships that could be construed as a potential conflict of interest.

Copyright (c) 2016 Fischler, Meert, Sculier and Berghmans. This is an open-access article distributed under the terms of the Creative Commons Attribution License (CC BY). The use, distribution or reproduction in other forums is permitted, provided the original author(s) or licensor are credited and that the original publication in this journal is cited, in accordance with accepted academic practice. No use, distribution or reproduction is permitted which does not comply with these terms. 